\title{
Evaluation of Arbuscular Mycorrhizal Fungi as Potential Determinants of Medicinal Plant Community Structure in Mihintale Sanctuary, Sri Lanka
}

\author{
Upamali P.A.T., Yapa P.N.* and Dissanayake R.B.N. \\ Faculty of Applied Sciences, Rajarata University of Sri Lanka, Mihintale, Sri Lanka \\ *pnyapa40@yahoo.co.uk
}

\begin{abstract}
Forests of Sri Lanka have higher density and species diversity of medicinal plants. There is an increasing world wide interest in medicinal plants due to growing recognition of natural products, being non toxic having no side effects and easy availability at affordable prices. Due to an increase demand for medicinal plants and to a loss and fragmentation of natural habitats medicinal plants of the Sri Lanka face a threat in the wild. Almost all natural plant communities except few plant families contain arbuscularmycorrhizal fungi (AMF). We hypothesized that thevaryingarbuscularmycorrhizal dependencycould have the potential to determine medicinal plant community structure in MihintaleSanctuary, Sri Lanka.

With the objective of testing above hypothesis we conducted a study where ten medicinal plant species in undisturbed site of the MihintaleSanctuarywas randomly selected. For the estimation of the abundance of medicinal plant species, five line transect of $100 \mathrm{~m}$ were randomly derived and calculations were done. Composite root samples of fine roots of each of the ten species were taken from all five line transects. Ten replicate root samples per one selected medicinal plant species were analysed for AMF colonization following the standard procedures of root staining and quantification. Further, along the different points of line transects moisture content, $\mathrm{pH}$ and organic carbon content were estimated. Non parametric analysis was followed to check whether there any significant difference among selected medicinal plant species for the abundance and percentage AMF colonization respectively. Multivariate analysis was performed to establish the relationship with the percentage mycorrhizal colonization and species abundance.
\end{abstract}

All the ten medicinal plants species selected for the present study had AMF associations in varying colonization levels, ranged from $81.43 \%$ in Elephantopus scaber to $28.92 \%$ in Morinda coreia.There was a significant difference among selected medicinal plant species for abundance $(p=0.031)$ and percentage AMF colonization $(p=0.029)$. For all the tested medicinal plants correlation studies were shown positive significant correlation at the 0.01 level. The results indicated that below ground native AMF community has the potential to determine medicinal plant community structure above ground in Mihintale Sanctuary.

Keywords: Arbuscularmycorrhizal fungi, Medicinal plants, Species abundance, Community structure 